\title{
Sperm motility and morphology changes in rats exposed to cadmium and diazinon
}

\author{
Maria Adamkovicova' ${ }^{1}$, Robert Toman², Monika Martiniakova ${ }^{3}$, Radoslav Omelka', Ramona Babosova ${ }^{3}$, \\ Vladimira Krajcovicova ${ }^{1}$, Birgit Grosskopf ${ }^{4 *}$ and Peter Massanyi ${ }^{5}$
}

\begin{abstract}
Background: Humans are ubiquitously exposed to multiple environmental contaminants. Consequences of combined action on the reproductive system remain unknown. This study aimed to assess single and joint effects of cadmium and diazinon exposure on sperm quality parameters.

Methods: Male adult Wistar rats were randomized into 4 groups of ten animals each. Group A was used as a control, animals from group B were exposed to cadmium (30 mg/L), rats from group $C$ were administered with diazinon (40 mg/L), and rats from group D were exposed simultaneously to cadmium (30 mg/L) and diazinon (40 mg/L) via drinking water for 90 days. Sperm morphology and motility were evaluated using a bright field microscope and a computer-assisted semen analysis.
\end{abstract}

Results: The percentage of motile spermatozoa and morphologically normal sperm was markedly reduced in rats from the group B. Rats from the C group showed an increase in velocity parameters, amplitude of lateral head displacement, decrease in beat-cross frequency, and an increase in abnormal sperm morphology. Simultaneous coexposure to cadmium and diazinon increased distance and velocity parameters, and amplitude of lateral head displacement. Reductions were observed in straightness, linearity, wobble, and beat-cross frequency. The decreased normal sperm morphology rates were related to defects of the sperm tail.

Conclusions: Exposure to cadmium and diazinon at relatively low doses impairs sperm quality and can reduce male fertility. Cadmium and diazinon caused significant changes on sperm morphology with varying effects on motility patterns. These parameters were significantly higher in the group D as compared to the group $C$. The findings have important implications for reproductive risk assessment of combined exposures to multiple chemicals.

Keywords: Sperm, Motility, Morphology, Rat, Cadmium, Diazinon

\section{Background}

Cadmium (Cd) is a globally widespread toxic element which has no known biological function. Environmental pollution with $\mathrm{Cd}$ can produce a wide range of adverse health effects in both experimental animals and humans [1]. Apart from occupational exposure, food is the main source of $\mathrm{Cd}$ for the non-smoking population. The accumulation of $\mathrm{Cd}$ over time can severely damage the lungs, liver, kidney, bone, and reproductive system [2, 3]. Male reproductive toxicity induced by $\mathrm{Cd}$ involves various mechanisms such as direct effect on the testicular tissue,

\footnotetext{
* Correspondence: birgit.grosskopf@biologie.uni-goettingen.de

${ }^{4}$ Institute of Zoology and Anthropology, Georg-August University, 37073

Göttingen, Germany

Full list of author information is available at the end of the article
}

altered accessory sex gland secretions, resulting in decreased semen quality and indirect endocrine effects, causing suppression of steroid biosynthesis $[4,5] . \mathrm{Cd}$ affects multiple cellular processes, including cell proliferation, differentiation, and apoptosis [6]. In the testis, disruption of intracellular junctions due to $\mathrm{Cd}$ toxicity on vascular system results in hemorrhage, edema, necrosis and germ cells damage [7, 8]. Another factor that may cause disruption of spermatogenesis in the testes is oxidative stress. The excessive production of reactive oxygen species (ROS) leads to decline observed in normal morphology, concentration, and motility of sperms $[9,10]$.

Diazinon (DZN) is an organophosphorus synthetic insecticide entering the environment from agricultural and household application of the chemical to control pest 
insects [11]. For the general population, dietary exposure to DZN residues, particularly in vegetables and fruits, is the most likely route of exposure. Following absorption into the body, DZN is bioactivated through desulfuration to oxygen analogues diazoxon, which is more toxic than the parent compound $[12,13]$. The primary effects of DZN are mediated through an inhibition of acetylcholinesterase in the peripheral and central nervous systems [14]. DZN is one of the most important insecticides that are associated with decreased semen quality in men [15]. Organophosphate insectides alter male reproductive function inducing spermatogenic disturbances through hormonal or genotoxic mechanisms [16]. Furthermore, the induction of oxidative stress associated with defective sperm function and reduced male fertility has been observed after DZN exposure $[17,18]$. Prolonged exposure to DZN alters semen quality and sperm chromatin, reduces sperm motility and viability, and increase sperm morphological abnormalities $[19,20]$.

Humans can be exposed simultaneously or sequentially to complex mixtures of environmental chemicals from numerous sources. Attention has recently been focused on adverse reproductive outcomes associated with widespread and permanent contamination by heavy metals and pesticides [21, 22]. However, the effects of potential interactions between different chemicals on the reproductive toxicity remain unknown [23]. Sperm motility and morphology parameters are very important semen characteristics [24]. Therefore, the present study was designed to determine the single and combined effects of $\mathrm{Cd}$ and DZN on sperm parameters in rats in relation to evaluate their potential interaction.

\section{Methods}

\section{Chemicals}

$\mathrm{Cd}$ in the form of cadmium chloride $\left(\mathrm{CdCl}_{2}\right)$, with purity $96 \%$, was purchased from Reachem, Slovak Republic. Pestanal grade DZN, analytical standard $\left(\mathrm{C}_{12} \mathrm{H}_{21} \mathrm{~N}_{2} \mathrm{O}_{3} \mathrm{PS}\right)$, with purity $99 \%$, was obtained from Sigma-Aldrich Laborchemikalien $\mathrm{GmbH}$, Germany.

\section{Animals}

The experiments were performed using male Wistar rats obtained from the accredited breeding and experimental laboratory (SK PC 50004, SUA Nitra). The rats were individually housed in plastic cages in an environment maintained at $20-24{ }^{\circ} \mathrm{C}, 55 \pm 10 \%$ humidity and 12 / $12 \mathrm{~h}$ cycle of light and darkness with access to food (feed mixture M3, Machal, Czech Republic) and drinking water ad libitum.

\section{Experimental design}

In a 90-day study of oral toxicity, the 4 week old Wistar rats were randomly assigned into four groups of ten males each. Group A of untreated rats served as the control group. Rats in the group B were exposed to $\mathrm{Cd}$ at $30 \mathrm{mg} / \mathrm{L}$ in drinking water. Rats in the group $\mathrm{C}$ were administered with $\mathrm{DZN}$ at $40 \mathrm{mg} / \mathrm{L}$ in drinking water. Rats in the group D were treated with $\mathrm{Cd}$ and DZN together in combination of their identical doses in drinking water. The average daily dose of $\mathrm{Cd}$ in the B group was $1.01 \mathrm{mg}$ per rat, the average estimated daily intake of DZN was $1.31 \mathrm{mg}$ per rat in the $\mathrm{C}$ group. In the group $\mathrm{D}$, the average daily oral intake of $\mathrm{Cd}$ was calculated as $0.96 \mathrm{mg}$ and the daily DZN intake was $1.28 \mathrm{mg}$. Dose regimen, duration and route of administration in this study were based on previously described research to induce toxicity but not mortality in animals $[25,26]$. The rats were observed daily for survival and clinical signs of toxicity. Individual body weights, food consumption, and water consumption were measured at weekly intervals. At the end of the treatment period, all animals were sacrificed and complete gross postmortem examinations were performed. Sperm were isolated from the left epididymis and sperm analysis was evaluated as previously described [24].

\section{Sperm motility analysis}

To evaluate spermatozoa motility parameters a computer assisted semen analysis - SpermVision ${ }^{\mathrm{TM}}$ CASA System (MiniTüb, Tiefenbach, Germany) with Olympus BX 51 phase contrast microscope (Olympus, Tokyo, Japan) was used. Sperm samples were diluted with physiological solution $(10 \mu \mathrm{l})$ and pipetted into a Makler Counting Chamber (depth $10 \mu \mathrm{m}$, Sefi Medical Instruments, Haifa, Israel) and immediately assessed. Within each of the measurement by the CASA system, motility parameters from minimum seven fields of Makler Counting Chamber were analysed and 1000 sperms were evaluated per sample. Motion parameters included the percentage of motile spermatozoa (MOT), the percentage of progressive motility (PROG), distance average path (DAP, $\mu \mathrm{m})$, distance curved line (DCL, $\mu \mathrm{m})$, distance straight line (DSL, $\mu \mathrm{m}$ ), velocity average path (VAP, $\mu \mathrm{m} / \mathrm{s}$ ), velocity curved line (VCL, $\mu \mathrm{m} / \mathrm{s}$ ), velocity straight line (VSL, $\mu \mathrm{m} / \mathrm{s}$ ), straightness (STR, \%), linearity (LIN, \%), wobble (WOB, \%), amplitude of lateral head displacement $(\mathrm{ALH}, \mu \mathrm{m})$, and beat cross frequency (BCF, $\mathrm{Hz})$.

\section{Sperm morphology analysis}

Assessment of sperm morphology was based on computerized techniques with PC morphometric software M.I.S. Quick Photo and using light microscope Olympus AX 70 Provis (Japan). After semen collection, samples were fixed with Hancock's solution and smears were prepared. The slides were stained with Giemsa's dye and submitted to analysis at $x 400$ magnification. A total of 500 spermatozoa from each rat were examined and individually 
scored normal or abnormal, according to the strict sperm morphology criteria. The morphological abnormalities were divided into head and tail defects. Sperm abnormalities of the mid-piece were included as part of assessment of the sperm tail. The percentages of normal and abnormal shaped sperms were calculated.

\section{Statistical analysis}

Differences were tested for statistical significance by oneway analysis of variance (ANOVA) and post hoc Scheffe's test using SAS 9.2 Enterprise Guide 4.3 software (SAS Institute Inc., Cary, North Carolina, USA). Data was expressed as means \pm standard deviation (SD) and were considered statistically significant when $P<0.05$.

\section{Results}

\section{Body weight, food and water intake}

No clinical signs indicative of systemic toxicity were observed in any animal during the study. There were no significant differences in final body weight, weekly food and water intakes among control and experimental groups, as shown in Table 1.

\section{Evaluation of sperm motility}

Results of epididymal sperm analysis of the rats from all groups are summarized in Table 2 . The sperm motility analysis showed significant changes in all motion parameters of rats from the group B. There was a significant decrease in MOT $(P<0.001)$ and PROG $(P<0.01)$. The results showed decreased distance parameters, including DAP $(P<0.01)$, DCL $(P<0.01)$, and DSL $(P<0.001)$. Similarly, parameters reflecting velocity characteristics demonstrated a significant reduction $(P<0.01)$. Cd also significantly decreased STR $(P<0.001)$, LIN $(P<0.001)$, WOB $(P<0.001)$, ALH $(P<0.05)$ and BCF $(P<0.001)$.

The sperm of rats from the group $C$ showed significant increases $(P<0.05)$ in VAP and VCL, consistently with ALH $(P<0.001)$. BCF values were significantly decreased $(P<0.01)$. No significant differences were observed for MOT, PROG, VSL, LIN, STR and distance parameters.

Compared with the control group, there was no significant difference in MOT and PROG parameters in the group D. However, there was a marked increase $(P<0.001)$ in all distance and velocity parameters. Furthermore, the mean values for ALH increased significantly $(P<0.001)$.
Conversely, significant decreases were detected in progression parameters VSL $(P<0.01)$, LIN $(P<0.001)$, and vigour parameters WOB $(P<0.001)$, and BCF $(P<0.001)$.

\section{Evaluation of sperm morphology}

The percentages of normal and abnormal spermatozoa are shown in Table 3. Morphological analysis of semen samples revealed a significant lower percentage of spermatozoa with normal morphology in all experimental groups $(P<0.001)$. The significantly increased $(P<0.01)$ incidence of sperm with abnormal head in group $B$ were detected. Moreover, the number of sperm head defects were significantly higher in the group $C(P<0.05)$. The common head defects include detached head and sperm with abnormal head number. Simultaneous coexposure to $\mathrm{Cd}$ and DZN did not produce any variation in the frequency of sperm head abnormalities. The percentage of sperm with normal tails significantly decreased $(P<0.001)$ in all exposed groups. The predominant types of abnormalities were sperm with knob-twisted flagellum and retained cytoplasmic droplets. The representative microphotographs of sperm morphology are shown in Fig. 1.

\section{Discussion}

In the present study, results indicate significant decline in sperm motility and morphology of the rats exposed to Cd. CASA based sperm motion analysis depict a significant decline in all evaluated motility parameters. Furthermore, normal sperm morphology was significantly affected by increased percentage of sperm with detached head and increased abnormal sperm tail morphology. These findings are similar to those reported from both animal studies $[27,28]$ and research involving humans $[4,29]$. The decrease in sperm concentration and motility, and the increase in dead and abnormal sperm of rats orally given $\mathrm{CdCl}_{2}$ at $5 \mathrm{mg} / \mathrm{kg}$ bw for 30 days were documented [27]. Similarly, subchronic exposure to $\mathrm{CdCl}_{2}$ at $40 \mathrm{mg} / \mathrm{l}$ for 30 days resulted in decreased sperm motility and impairment of spermatogenesis in rats [28]. Various mechanisms may explain reduced sperm quality induced by $\mathrm{Cd}$. The alteration in sperm parameters could be attributed to direct effect on testicular tissue which leads to reproductive dysfunction such as reduced sperm count, motility and morphology [30]. Cd specifically disrupts Sertoli-germ cell tight junctions and thus leads

Table 1 Body weight, food and water intake

\begin{tabular}{lllll}
\hline Group & A & B & C & D \\
Parameters & Mean \pm SD & Mean \pm SD & Mean \pm SD & Mean \pm SD \\
\hline Body Weight $(\mathrm{g})$ & $405.00 \pm 52.65$ & $426.67 \pm 25.25$ & $406.00 \pm 24.70$ & $427.78 \pm 19.22$ \\
Food Intake $(\mathrm{g})$ & $155.17 \pm 27.26$ & $169.04 \pm 30.56$ & $147.32 \pm 23.32$ & $148.09 \pm 21.35$ \\
Water Intake $(\mathrm{ml})$ & $254.49 \pm 32.50$ & $252.28 \pm 31.41$ & $239.63 \pm 33.63$ & $233.39 \pm 31.61$ \\
\hline
\end{tabular}

${ }^{*} P<0.05 ;{ }^{* *} P<0.01 ;{ }^{* * *} P<0.001$ 
Table 2 Sperm motility analysis

\begin{tabular}{lllll}
\hline Group & A & B & C & D \\
Parameters & Mean \pm SD & Mean \pm SD & Mean \pm SD & Mean \pm SD \\
\hline MOT $(\%)$ & $50.31 \pm 9.15$ & $16.72 \pm 20.38^{* * *}$ & $39.87 \pm 20.99$ & $53.03 \pm 8.58$ \\
PROG $(\%)$ & $27.69 \pm 7.34$ & $6.97 \pm 15.23^{* *}$ & $20.00 \pm 14.54$ & $29.99 \pm 6.85$ \\
DAP $(\mu \mathrm{m})$ & $21.95 \pm 3.29$ & $10.39 \pm 9.61^{* *}$ & $24.55 \pm 3.57$ & $32.32 \pm 2.57^{* * *}$ \\
DCL $(\mu \mathrm{m})$ & $33.91 \pm 4.98$ & $16.14 \pm 14.57^{* *}$ & $37.54 \pm 5.41$ & $55.31 \pm 4.70^{* * *}$ \\
DSL $(\mu \mathrm{m})$ & $17.65 \pm 2.15$ & $7.65 \pm 6.36^{* * *}$ & $19.42 \pm 3.37$ & $24.34 \pm 2.12^{* * *}$ \\
VAP $(\mu \mathrm{m} / \mathrm{s})$ & $52.73 \pm 9.25$ & $25.43 \pm 24.69^{* *}$ & $62.44 \pm 9.34^{*}$ & $80.00 \pm 6.37^{* * *}$ \\
VCL $(\mu \mathrm{m} / \mathrm{s})$ & $81.10 \pm 13.88$ & $39.57 \pm 37.33^{* *}$ & $95.01 \pm 14.47^{*}$ & $134.74 \pm 11.30^{* * *}$ \\
VSL $(\mu \mathrm{m} / \mathrm{s})$ & $42.37 \pm 5.92$ & $18.76 \pm 16.28^{* *}$ & $49.16 \pm 8.52$ & $60.50 \pm 5.14^{* * *}$ \\
STR $(\%)$ & $0.81 \pm 0.04$ & $0.35 \pm 0.24^{* * *}$ & $0.79 \pm 0.04$ & $0.75 \pm 0.02^{* *}$ \\
LIN $(\%)$ & $0.24 \pm 0.18^{* * *}$ & $0.53 \pm 0.04$ & $0.45 \pm 0.02^{* * *}$ \\
WOB $(\%)$ & $0.53 \pm 0.04$ & $0.31 \pm 0.23^{* * *}$ & $0.66 \pm 0.03$ & $0.60 \pm 0.02^{* * *}$ \\
ALH $(\mu \mathrm{m})$ & $0.65 \pm 0.03$ & $2.52 \pm 1.93^{*}$ & $6.76 \pm 1.06^{* * *}$ & $9.74 \pm 0.69^{* * *}$ \\
BCF $(\mathrm{Hz})$ & $4.52 \pm 1.26$ & $7.99 \pm 5.79^{* * *}$ & $17.95 \pm 2.73^{* *}$ & $16.72 \pm 1.85^{* * *}$ \\
\hline
\end{tabular}

MOT motility, PROG progressive motility, DAP distance average path, DCL distance curved line, DSL distance straight line, VAP velocity average path, VCL velocity curved line, VSL velocity straight line, STR straightness, $L I N$ linearity, WOB wobble, $A L H$ amplitude of lateral head displacement, $B C F$ beat cross frequency; ${ }^{*} P<0.05$; ${ }^{* *} P<0.01 ;{ }^{* * *} P<0.001$

to the failure of spermatogenesis. Profound testicular damage displays destruction of the seminiferous tubules and progressive sloughing of immature germ cells which result in abnormalities in early sperm development $[8,31]$. Furthermore, low dose exposure to $\mathrm{Cd}$ affects steroid hormone actions involved in the regulation of reproductive processes. The maintenance of normal steroidogenic enzymes activity is required for proper testicular steroidogenesis and spermatogenesis. The decrease in sperm count and quality is correlated with decrease in testosterone levels and oxidative damage as evident from suppressed antioxidant enzyme activities [5, 32].

According to results from the CASA analysis, different motility patterns were identified after DZN exposure. Rats from the group $\mathrm{C}$ showed a significant reduction in $\mathrm{BCF}$, but no apparent effect on MOT and PROG were found. Stimulation of motility was characterized by an increase of ALH and velocity parameters VAP and VCL. The percentage of morphologically normal sperm was lowered predominantly due to significantly higher number of sperm with abnormal tail morphology. Furthermore, significant increased incidence of abnormal detached sperm head was detected. These findings indicate that the exposure to DZN caused a severe disturbance of spermatogenesis, with a marked decline in sperm quality. Mice exposed to DZN at a dose $3 \mathrm{mg} / \mathrm{kg} /$ day for 6 weeks showed increased degenerate germ cells in seminiferous tubule and sperm morphological abnormalities [33]. Similarly, continuous oral administration of DZN to male rats at dose levels of 1.5 or $3 \mathrm{mg} / \mathrm{kg} /$ day for 65 days caused impaired reproductive function indicated by alterations in sperm motility, viability and morphology [34]. The induction of abnormal sperms was assumed to be a result of a direct effect of DZN on testicular tissue. The mice exposed to 4.1 and $8.2 \mathrm{mg} / \mathrm{kg}$ bw/day provoked severe alterations in the seminiferous tubules, including derangement and sloughing of the germ cells, the vacuolization of germ cell cytoplasm and the disruption of spermatogenic cells [16]. Although sperm DNA is normally resistant to aggressors because of its highly compacted structure, it has been proposed as a target of organophosphates [35]. Nuclear protamine phosphorylation caused by DZN exposure contributes to alterations in both sperm chromatin condensation and DNA integrity which has a negative impact on male fertility potential $[19,36]$.

Simultaneous coexposure to $\mathrm{Cd}$ and DZN displayed a higher incidence of hyperactivated-like motility than

Table 3 Sperm morphology analysis

\begin{tabular}{lllll}
\hline Group & A & B & C & D \\
Parameters & Mean \pm SD & Mean \pm SD & Mean \pm SD & Mean \pm SD \\
\hline Normal Morphology & $97.44 \pm 0.94$ & $91.09 \pm 2.91^{* * *}$ & $91.60 \pm 3.37^{* * *}$ & $94.56 \pm 1.12^{* * *}$ \\
Abnormal Head & $1.74 \pm 0.69$ & $3.87 \pm 1.64^{* *}$ & $3.73 \pm 2.49^{*}$ & $1.84 \pm 0.61$ \\
Abnormal Tail & $0.82 \pm 0.39$ & $5.04 \pm 2.65^{* * *}$ & $4.67 \pm 2.06^{* * *}$ & $3.6 \pm 1.04^{* * *}$ \\
\hline
\end{tabular}

${ }^{*} P<0.05$; ${ }^{*} P<0.01 ;{ }^{* * *} P<0.001$ 

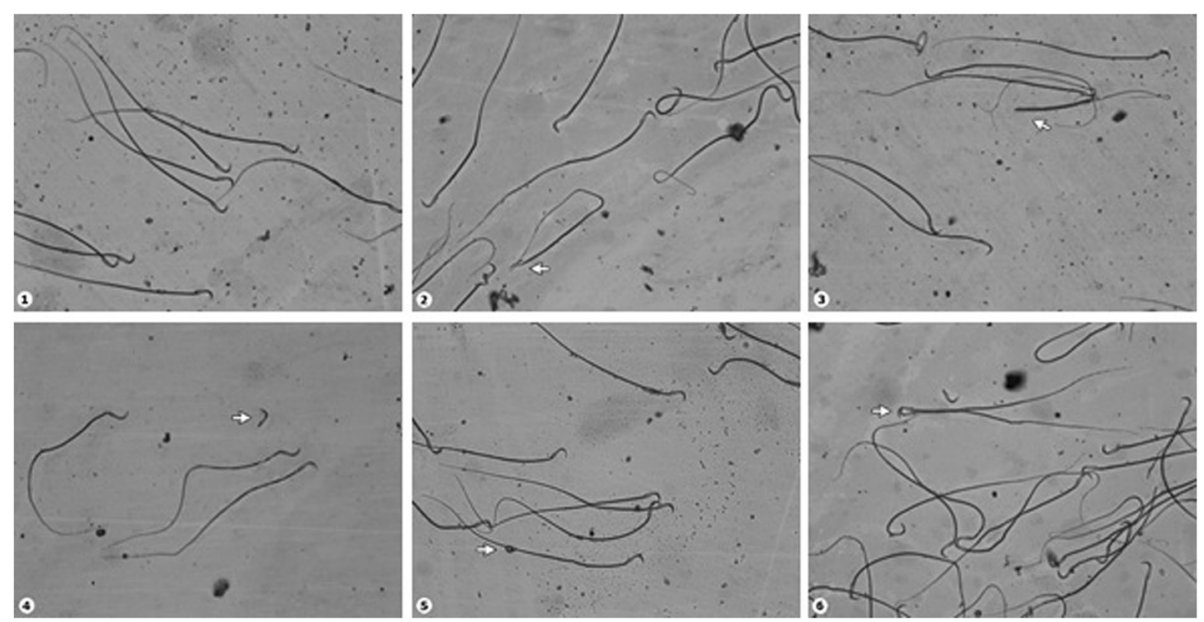

Fig. 1 Microphotographs illustrating morphologically normal sperm and various sperm defects. 1 - Normal morphology; 2 -Bent neck; 3 - Headless tail; 4 - Detached head; 5 - Cytoplasmic droplet; 6 - Pairing phenomenon (Giemsa stain; original magnification $\times 400$ )

caused by DZN alone. The observed changes included significant increase in all measured distance, velocity parameters, and ALH. On the contrary, reductions were observed in progression parameters STR, LIN, and WOB, and vigour parameter $\mathrm{BCF}$, while $\mathrm{MOT}$ and PROG were unchanged. Increased sperm velocity, increased ALH, and decreased LIN are known to reflect the increased vigor and asymmetrical movement of sperm tail which have been consequently related to hyperactivated motility [37]. Decrease in normal sperm morphology was linked to significantly increased sperm with abnormal tails. Interestingly, simultaneous coexposure did not produce any adverse effect on sperm head morphology. It is important to note that head and midpiece morphometric parameters may impact on motility patterns including VAP, VSL, LIN, STR, and BCF [38]. The possibility that DZN may cross the epididymal epithelium based on its lipophilic properties and reach the stored spermatozoa would explain its damaging effects on sperm structure and function [39]. It is known that combined exposure to pesticides and the heavy metals may alter toxic effects of the single compounds. A significant interaction between $\mathrm{Cd}$ and propoxur, carbamate insecticide, was detected on hematological, immune function and nerve conduction velocity [40]. Semen samples exposed to $\mathrm{Cd}$, lead, chlorpyrifos, endosulfan showed reduced PROG, and acrosomal integrity. The fertilization capabilities of sperm were significantly reduced because of spermatozoa movement dysfunction [41].

In general, oxidative damage has been involved in the genotoxic and reproductive effects of various metals and organophosphorus pesticides. Cd and DZN toxicity involves formation of ROS, suggesting that oxidative stress plays a major role after their coexposure. It has been documented that combined exposure to arsenic and organophosphates result in increased levels of ROS in blood and tissues [42]. Increased lipid peroxidation has been correlated with alteration of sperm membrane, decreased sperm motility, and fertilization potential [27, 43]. Furthermore, DZN can alter semen quality and sperm DNA integrity or its associated proteins in the testis by generation of ROS which could intensify testicular dysfunction [18]. Increased rate of sperms with retained cytoplasmic residues may lead to increased ROS production and altered sperm quality [44]. Sperm membrane contains a characteristic high level of unsaturated fatty acids which makes spermatozoa particularly susceptible to oxidative damage [45]. Low levels of ROS produced by spermatozoa are needed for physiological processes involving sperm capacitation and the acrosome reaction. Excessive generation of ROS leads to reduced mitochondrial membrane potential and is associated with a decreasing energy availability, which may impede sperm motility [46, 47]. The most interesting aspect of this study was the fact, that concurrent administration of $\mathrm{Cd}$ and DZN elevated velocity and distance parameters together with ALH, in contrast with the decreased motility parameters than did $\mathrm{Cd}$ alone. The present findings have important implications for reproductive risk assessment in determining the interactive effects of combined exposure on sperm quality in the adult population. However, a better understanding of processes and pathways involved in the toxic actions of $\mathrm{Cd}$ and DZN is necessary and would require further experiments.

\section{Conclusions}

The present study demonstrates that low doses of $\mathrm{Cd}$ and DZN impair sperm quality, and can reduce male fertility potential. Sperm motility was markedly decreased in rats exposed to $\mathrm{Cd}$. Sperm distance, velocity parameters, and ALH were significantly higher in the combined 
group than caused by DZN given alone. The decrease in normal sperm morphology due to increased rate of sperm with head or tail defects was found after single exposure to $\mathrm{Cd}$ and DZN. Simultaneous coexposure increased sperms with abnormal tail morphology. The results of this study could be beneficial for evaluating reproductive health risks of combined exposure to multiple chemicals.

\begin{abstract}
Abbreviations
$\mathrm{ALH}$, amplitude of lateral head displacement; BCF, beat cross frequency; CASA, computer assisted semen analysis; $\mathrm{Cd}$, cadmium; $\mathrm{CdCl}_{2}$, cadmium chloride; DAP, distance average path; DCL, distance curved line; DSL, distance straight line; DZN, diazinon; LIN, linearity; MOT, motility; PROG, progressive motility; ROS, reactive oxygen species; STR, straightness; VAP, velocity average path; $\mathrm{VCL}$, velocity curved line; VSL, velocity straight line; WOB, wobble
\end{abstract}

\section{Acknowledgements}

Not applicable.

\section{Funding}

This work was supported by Research Centre AgroBioTech built in accordance with the project Building Research Centre „AgroBioTech"ITMS 26220220180. This study was also supported by the grant KEGA 031UKF-4/2016

\section{Availability of data and material}

All datasets on which the conclusions of the paper rely are available to readers.

\section{Authors' contributions}

MA analysed data and wrote the manuscript. RT conceived, designed and coordinated the study. MM drafted and revised the manuscript. RO performed the data management and statistics. RB conducted morphological analysis. VK performed sample collection and preparation. BG performed the final correction of the manuscript and corresponds with co-authors. PM carried out CASA analysis. All authors read and approved the final manuscript.

\section{Competing interests}

The authors declare that they have no competing interests.

\section{Consent for publication}

Not applicable.

\section{Ethics approval and consent to participate}

Institutional and national guidelines for the care and use of animals were followed. All experimental procedures were approved by the State Veterinary and Food Institute of Slovak Republic, no. 3398/11-221/3.

\section{Author details}

'Department of Botany and Genetics, Constantine the Philosopher University, 94974 Nitra, Slovakia. ${ }^{2}$ Department of Veterinary Disciplines, Slovak University of Agriculture, 94976 Nitra, Slovakia. ${ }^{3}$ Department of Zoology and Anthropology, Constantine the Philosopher University, 94974 Nitra, Slovakia. ${ }^{4}$ Institute of Zoology and Anthropology, Georg-August University, 37073 Göttingen, Germany. ${ }^{5}$ Department of Animal Physiology, Slovak University of Agriculture, 94976 Nitra, Slovakia.

Received: 17 June 2016 Accepted: 28 July 2016

Published online: 08 August 2016

\section{References}

1. McMurray $C T$, Tainer JA. Cancer, cadmium and genome integrity. Nat Genet. 2003:34:239-41.

2. Jarup $L$, Akesson A. Current status of cadmium as an environmental health problem. Toxicol Appl Pharmacol. 2009;238:201-8.

3. Satarug S, Garrett SH, Sens MA, Sens DA. Cadmium, environmental exposure, and health outcomes. Cien Saude Colet. 2011;16:2587-602.
4. Benoff S, Hauser R, Marmar JL, Hurley IR, Napolitano B, Centola GM. Cadmium concentrations in blood and seminal plasma: correlations with sperm number and motility in three male populations (infertility patients, artificial insemination donors, and unselected volunteers). Mol Med. 2009;15:248-62.

5. Pandya C, Pillai P, Nampoothiri LP, Bhatt N, Gupta S, Gupta S. Effect of lead and cadmium co-exposure on testicular steroid metabolism and antioxidant system of adult male rats. Andrologia. 2012;44 Suppl 1:813-22.

6. Waisberg M, Joseph P, Hale B, Beyersmann D. Molecular and cellular mechanisms of cadmium carcinogenesis. Toxicology. 2003;192:95-117.

7. Prozialeck WC, Edwards JR, Nebert DW, Woods JM, Barchowsky A, Atchison WD. The vascular system as a target of metal toxicity. Toxicol Sci. 2008:102:207-18.

8. Siu ER, Mruk DD, Porto CS, Cheng CY. Cadmium-induced testicular injury. Toxicol Appl Pharmacol. 2009;238:240-9.

9. Meeker JD, Rossano MG, Protas B, Diamond MP, Puscheck E, Daly D, Paneth N, Wirth JJ. Cadmium, lead, and other metals in relation to semen quality: human evidence for molybdenum as a male reproductive toxicant. Environ Health Perspect. 2008;116:1473-9.

10. Monsefi M, Alaee S, Moradshahi A, Rohani L. Cadmium-induced infertility in male mice. Environ Toxicol. 2010;25:94-102.

11. Colovic M, Krstic D, Petrovic S, Leskovac A, Joksic G, Savic J, Franko M, Trebse $P$, Vasic $V$. Toxic effects of diazinon and its photodegradation products. Toxicol Lett. 2010;193:9-18.

12. Kappers WA, Edwards RJ, Murray S, Boobis AR. Diazinon is activated by CYP2C19 in human liver. Toxicol Appl Pharmacol. 2001;177:68-76.

13. Mutch E, Williams FM. Diazinon, chlorpyrifos and parathion are metabolised by multiple cytochromes P450 in human liver. Toxicology. 2006;224:22-32.

14. Costa LG. Current issues in organophosphate toxicology. Clin Chim Acta. 2006;366:1-13.

15. Swan SH, Kruse RL, Liu F, Barr DB, Drobnis EZ, Redmon JB, Wang C, Brazil C, Overstreet JW. Semen quality in relation to biomarkers of pesticide exposure. Environ Health Perspect. 2003;111:1478-84.

16. ElMazoudy RH, Attia AA. Endocrine-disrupting and cytotoxic potential of anticholinesterase insecticide, diazinon in reproductive toxicity of male mice. J Hazard Mater. 2012;209-210:111-20.

17. Bustos-Obregon E, Gonzalez JR, Espinoza O. Melatonin as protective agent for the cytotoxic effects of diazinon in the spermatogenesis in the earthworm Eisenia foetida. Ital J Anat Embryol. 2005;110(2 Suppl 1):159-65.

18. Leong CT, D'Souza UJ, Iabal M, Mustapha ZA. Lipid peroxidation and decline in antioxidant status as one of the toxicity measures of diazinon in the testis. Redox Rep. 2013;18:155-64

19. Sanchez-Pena LC, Reyes BE, Lopez-Carrillo L, Recio R, Moran-Martinez J, Cebrian ME, Quintanilla-Vega B. Organophosphorous pesticide exposure alters sperm chromatin structure in Mexican agricultural workers. Toxicol Appl Pharmacol. 2004;196:108-13.

20. Pina-Guzman B, Solis-Heredia MJ, Quintanilla-Vega B. Diazinon alters sperm chromatin structure in mice by phosphorylating nuclear protamines. Toxicol Appl Pharmacol. 2005;202:189-98.

21. Kumar S. Occupational exposure associated with reproductive dysfunction. J Occup Health. 2004;46:1-19.

22. Wan HT, Mruk DD, Wong CK, Cheng CY. Targeting testis-specific proteins to inhibit spermatogenesis: lesson from endocrine disrupting chemicals. Expert Opin Ther Targets. 2013;17:839-55.

23. Wade MG, Foster WG, Younglai EV, McMahon A, Leingartner K, Yagminas A, Blakey D, Fournier M, Desaulniers D, Hughes CL. Effects of subchronic exposure to a complex mixture of persistent contaminants in male rats: systemic, immune, and reproductive effects. Toxicol Sci. 2002;67:131-43.

24. Perreault SD, Cancel AM. Significance of incorporating measures of sperm production and function into rat toxicology studies. Reproduction. 2001; 121:207-16.

25. Agency for Toxic Substances and Disease Registry (ATSDR). Toxicologica profile for Diazinon. Atlanta: U.S. Department of Health and Human Services, Public Health Service; 2008.

26. Agency for Toxic Substances and Disease Registry (ATSDR). Toxicological profile for Cadmium. Atlanta: U.S. Department of Health and Human Services, Public Health Service; 2012.

27. El-Demerdash FM, Yousef MI, Kedwany FS, Baghdadi HH. Cadmium-induced changes in lipid peroxidation, blood hematology, biochemical parameters and semen quality of male rats: protective role of vitamin $\mathrm{E}$ and beta-carotene. Food Chem Toxicol. 2004;42:1563-71. 
28. Amara S, Abdelmelek H, Garrel C, Guiraud P, Douki T, Ravanat JL, Favier A, Sakly M, Ben RK. Preventive effect of zinc against cadmium-induced oxidative stress in the rat testis. J Reprod Dev. 2008;54:129-34.

29. Wang YX, Sun Y, Feng W, Wang P, Yang P, Li J, Huang Z, Chen YJ, Liu C, Sun L, Yue J, Gu LJ, Zeng Q, Lu WQ. Association of urinary metal levels with human semen quality: A cross-sectional study in China. Environ Int. 2016;91:51-9.

30. de Souza Predes F, Diamante MA, Dolder H. Testis response to low doses of cadmium in Wistar rats. Int J Exp Pathol. 2010;91:125-31.

31. Zhang M, He Z, Wen L, Wu J, Yuan L, Lu Y, Guo C, Zhu L, Deng S, Yuan H. Cadmium suppresses the proliferation of piglet Sertoli cells and causes their DNA damage, cell apoptosis and aberrant ultrastructure. Reprod Biol Endocrinol. 2010;8:97.

32. Acharya UR, Mishra M, Patro J, Panda MK. Effect of vitamins C and E on spermatogenesis in mice exposed to cadmium. Reprod Toxicol. 2008;25:84-8.

33. Wang D, Kamijima M, Okamura A, Ito Y, Yanagiba Y, Jia XF, Naito H, Ueyama J, Nakajima T. Evidence for diazinon-mediated inhibition of cis-permethrin metabolism and its effects on reproductive toxicity in adult male mice. Reprod Toxicol. 2012;34:489-97.

34. Abd el-Aziz MI, Sahlab AM, Abd el-Khalik M. Influence of diazinon and deltamethrin on reproductive organs and fertility of male rats. Dtsch Tierarztl Wochenschr. 1994;101:230-2.

35. Pina-Guzman B, Solis-Heredia MJ, Rojas-Garcia AE, Uriostegui-Acosta M, Quintanilla-Vega B. Genetic damage caused by methyl-parathion in mouse spermatozoa is related to oxidative stress. Toxicol Appl Pharmacol. 2006:216:216-24.

36. Salazar-Arredondo E, de Jesus Solis-Heredia M, Rojas-Garcia E, Hernandez-Ochoa I, Quintanilla-Vega B. Sperm chromatin alteration and DNA damage by methylparathion, chlorpyrifos and diazinon and their oxon metabolites in human spermatozoa. Reprod Toxicol. 2008;25:455-60.

37. Cancel AM, Lobdell D, Mendola P, Perreault SD. Objective evaluation of hyperactivated motility in rat spermatozoa using computer-assisted sperm analysis. Hum Reprod. 2000;15:1322-8

38. Gil MC, García-Herreros M, Baron FJ, Aparicio IM, Santos AJ, Garcia-Marin LJ. Morphometry of porcine spermatozoa and its functional significance in relation with the motility parameters in fresh semen. Theriogenology. 2009; 71:254-63.

39. Sarabia L, Maurer I, Bustos-Obregon E. Melatonin prevents damage elicited by the organophosphorous pesticide diazinon on mouse sperm DNA. Ecotoxicol Environ Saf. 2009;72:663-8.

40. Institoris L, Papp A, Siroki O, Banerjee BD, Desi I. Immuno- and neurotoxicological investigation of combined subacute exposure with the carbamate pesticide propoxur and cadmium in rats. Toxicology. 2002:178:161-73.

41. Selvaraju S, Nandi S, Gupta PS, Ravindra JP. Effects of heavy metals and pesticides on buffalo (Bubalus bubalis) spermatozoa functions in vitro. Reprod Domest Anim. 2011;46:807-13.

42. Dwivedi N, Flora SJ. Concomitant exposure to arsenic and organophosphates on tissue oxidative stress in rats. Food Chem Toxicol. 2011;49:1152-9.

43. Tvrda E, Knazicka Z, Lukacova J, Schneidgenova M, Goc Z, Gren A, Szabo C, Massanyi P, Lukac N. The impact of lead and cadmium on selected motility, prooxidant and antioxidant parameters of bovine seminal plasma and spermatozoa. J Environ Sci Health A Tox Hazard Subst Environ Eng. 2013:48:1292-300.

44. Kefer JC, Agarwal A, Sabanegh E. Role of antioxidants in the treatment of male infertility. Int J Urol. 2009;16:449-57.

45. Gravance CG, Garner DL, Miller MG, Berger T. Flow cytometric assessment of changes in rat sperm mitochondrial function after treatment with pentachlorophenol. Toxicol In Vitro. 2003;17:253-7.

46. Wang X, Sharma RK, Gupta A, George V, Thomas AJ, Falcone T, Agarwal A. Alterations in mitochondria membrane potential and oxidative stress in infertile men: a prospective observational study. Fertil Steril. 2003;80 Suppl 2: 844-50.

47. Tremellen K. Oxidative stress and male infertility - a clinical perspective. Hum Reprod Update. 2008;14:243-58

\section{Submit your next manuscript to BioMed Central and we will help you at every step:}

- We accept pre-submission inquiries

- Our selector tool helps you to find the most relevant journal

- We provide round the clock customer support

- Convenient online submission

- Thorough peer review

- Inclusion in PubMed and all major indexing services

- Maximum visibility for your research

Submit your manuscript at www.biomedcentral.com/submit
O) Biomed Central 